science at Harvard over a period of sixty-cight years ; Dr. Boas follows with an account of her happy experience in giving courses open to all upperelass university students in an Arts and Science School.

Prof. Guerlac gives an eloquent and convincing exposition of the function of the study of the history and philosophy of seience in promoting truo education.

It should be added that exceptionally full bibliographies are attached to all the papers. Space permits no adequate account of the important material packed into this volume. Both the conference and the publication were sponsored financially by the National Science Foundation of the United States and by the Research Committee of the University of Wisconsin.

Dorothea WaLey Singer

\section{ELECTRICAL CHARACTERISTICS OF THE EARTH'S STRATA}

Overvoltage Research and Geophysical Applications Edited by James R. Wait. (International Series of Monographs on Earth Scionces, Vol. 4.) Pp. viii + 158. (London and New York: Pergamon Press, 1959.) 55s. net.

MASUREMENTS of the electrical character1 istics of the Earth's strata indicate the existence of several interrelated phenomena, which have been discussed from time to time in the literature. One of the offects is the potential which can be observed between two non-polarizable electrodes immersed in a porous medium, after the interruption of an applied step function current. This induced potential has a considerable bearing on the transiont and frequency response of the medium. However, the phenomenon has, with a few exceptions, received scant attention.

The monograph edited by J. R. Wait consists of a collection of papers on the various aspects of induced potential. Various hypotheses for tho occurrence of the normal effect observable in all naturally occurring porous media are fully discussed, and results of experimental work designed to test these hypotheses are given.

Tho omphasis of the majority of the papors is given to the geophysical application of the abnormal overvoltage effect observed in a porous medium containing electrically conducting particles, that is, metallic ores.

Theorics of the transient and frequency response characteristics of such media are suggested, and the results of both laboratory and field investigations are given and discussed in relation to the suggested theoretical treatments. A short but useful paper on the fiold equipment required for prospocting for metallic ore bodies by the overvoltage method is included.

Some of the hypotheses advanced and indeed some of the practical results reported do not altogether agree with other published data on the subject. These differences are, however, mainly in degree rather than in fundamental concept. There appears to be, for example, some discrepancy between the discussion of the variation of measured conductivity of porous media with frequeney, when this is compared with earlier reports. This discrepancy may be real and, in fact, represent a difference in the response obtained from porous media with and without conducting particles.

The authors have given factual reports of the results of a coneerted attack on the problem of the overvoltage phenomenon and its practical application to geophysical prospecting. The individual papers are woll presented and the various discussions are logical and thought-provolking. The collection is well worth study by all research geophysicists, and should be read by anyone concerned with the flow of electrical current through Earth strata. P. THReADGorn

\section{NATURAL PRODUCTS}

Konstitution und Vorkommen der organischen Pflanzenstoffe (exclusive Alkaloide)

Von Dr. Walter Karrer. (Lehrbücher und Monographien aus dem Gebiete der exakten Wissen. schaften. Chemische Reihe, Band 12.) Pp. 1207. (Basel und Stuttgart: Birkhäuser Vorlag, 1958.) 136 Swiss francs; 136 D.M.

N

ATURALLY occurring organic compounds have fascinated chemists for very many years. Their. interest began with substances possessing some easily recognizable property, such as colour, smell, bitterness, or toxicity, but to-day it ranges through the whole spectrum of natural products. In spite of this interest and the current rapid developments in an understanding of the biogenesis of such compounds, there has been no up-to-date dictionary of natural products. Although monographs are available for some limited groups such as carbohydrates, alkaloids, steroids and carotenoids, in the case of many groups, or even individual compounds, the collection of com. prehensive information has entailed a long and tedious literature search. Dr. Walter Karrer has now eased this difficulty to a considerable extent. He has collected together details of organic compounds of known, or apparently known, structure found in plants, other than alkaloids. Even with these limitations about 2,700 natural products are described, ranging from hydrocarbons through depsides, carotenoids and terpenes to nitriles, pyrimidines and nucleotides.

The structural formula of each compound is given, as well as details of its distribution in the plant world. Key references to the elucidation of structure and synthesis are also listed. The information given about those groups of compounds with which I am familiar is accurate and comprehensive, the literature being covered to 1956, and the author is to be congratulated on the immense task which he has suecessfully undertaken.

For those concerned with structural elucidation of natural products, with their pharmacological activity, or with the biosynthesis of organic compounds, the appearance of this volume emphasizes the need for an even more complete dictionary of all natural products. Many compounds have been isolated which are inadequately described in the literature or the structure of which is still unknown. Often the same compound is deseribed under different names. If some chemist would collect together the information about these compounds with the same thoroughness that Dr. Karrer has shown in the present volume, he would perform an invaluable service.

'T. G. Halsali. 